\title{
PENGARUH MODEL PEMBELAJARAN TAKE AND GIVE TERHADAP HASIL BELAJAR SISWA TEMA VIII KELAS III SD RK BUDI LUHUR MEDAN
}

\author{
Jontono Samosir, Regina Sipayung, Reflina Sinaga, Darinda Sofia Tanjung \\ Surel : samosirjhontono@gmail.com
}

\begin{abstract}
This study aims to determine the effect of the Take and Give learning model on student learning outcomes with the PrajaMuda Karana theme in grade III SD RK Budi Luhur Medan. The research method used is an experimental method with quantitative research. To obtain the required data, data collection was used in the form of a test of 30 questions, a questionnaire of 17 statements, and documentation. The research at SD RK Budi Luhur Medan in class III was carried out from 17 to 18 May 2021. The number of samples was 30 students based on saturated sampling technique, based on the analysis, the pre test results were obtained with an average score of 68.73 in the sufficient category, the post test results with a score of 68.73 . an average of 86.7 in very good category and the Take and Give learning model questionnaire with an average value of $63.3 \%$ in the high category. The results of the correlation analysis of the effect of the Take and Give learning model on student learning outcomes obtained a correlation value of rcount $=0.578$ with rtable $=0.361$. Thus, the value of rcount is greater than the value of rtable, so the correlation is very significant. Hypothesis testing with t-test obtained tcount $=3.268$ with ttable $=1.697$ at a significant level of 0.05. It can be concluded that there is an effect of the Take and Give learning model on student learning outcomes with the theme of PrajaMuda Karana for grade III SD RK Budi Luhur Medan Denai.
\end{abstract}

Keywords: Take and Give Model, Learning Outcomes, Quantitative

\begin{abstract}
ABSTRAK
Penelitian ini bertujuan untuk mengetahui pengaruh model pembelajaran Take and Give terhadap hasil belajar siswa tema praja muda karanadi kelas III SD RK Budi Luhur Medan. Metode penelitian yang digunakan adalah metode eksperimen dengan jenis penelitian kuantitatif. Untuk memperoleh data yang diperlukan menggunakan pengumpulan data berupa test 30 soal, angket 17 pernyataan, dan dokumentasi. Penelitian di SD RK Budi Luhur Medan pada kelas III dilaksanakan 17 sampai 18 mei 2021. Jumlah sampel sebanyak 30 siswa berdasarkan tekniksampling jenuh, berdasarkan analisis diperoleh hasil pre test dengan nilai rata-rata 68,73 dengan kategori cukup, hasil post tes dengan nilai rata-rata 86,7 kategori baik sekali dan angket model pembelajaran Take and Give dengannilai rata-rata 63,3\% kategori tinggi. Hasil analisis korelasi pengaruh model pembelajaran Take and Give terhadap hasil belajar siswa diperoleh nilai korelasi $r_{\text {hitung }}=0,578$ dengan $r_{\text {tabel }}=0,361$. Dengan demikian nilai $r_{\text {hitung }}$ lebih besar dari pada nilai $r_{\text {tabel }}$ maka korelasi sangat signifikan. Uji hipotesis dengan uji $\mathrm{t}$ diperoleh $\mathrm{t}_{\text {hitung }}=$ 3,268 dengan $t_{\text {tabel }}=1,697$ pada taraf signifikan 0,05. Dapat disimpulkan adanya pengaruh model pembelajaran Take and Give terhadap hasil belajar siswa tema praja muda karana kelas III SD RK Budi Luhur Medan Denai.
\end{abstract}

Kata Kunci: Model Take and Give, Hasil Belajar, Kuantitatif 



\section{PENDAHULUAN}

Pendidikan merupakan sebuah usaha sadar yang terencana untuk mengembangkan suasana belajar dan proses kegiatan pembelajaran agar siswa dapat secara aktif untuk mengembangkan potensi yang ada didalam dirinya untuk memiliki beberapa kekuatan spritual keagamaan, lalu pengendalian diri, masyarakat, bangsa serta negara.

Pada kegiatan pendidikan di sekolah dimana proses kegiatan pembelajaran adalah kegiatan yang sangat berperan penting bagi siswa. Keberhasilan atau tidaknya dalam mencapai pendidikan pembelajaran itu dilihat dari seorang tenaga pengajar dalam proses menyampaikan pembelajaran. Dalam proses pembelajarannya guru berperan penting untuk bisa menyalurkan ilmu yang terdapat dalam dirinya kepada peserta didiknya.

Pembelajaran yang berada pada tingkatan SD tentunya berbeda dengan di SMP/SMA. Siswa sangat bergantung dalam pembelajaran dengan guru. Sebagai salah seorang tenaga pendidik di tingkatan SD seharusnya mampu memberikan ruang bagi peserta didik untuk mampu mengembangkan kemandirian siswa, dan memberikan motivasi dalam mengembangkan pengetahuan dan keterampilan serta kemampuan berpikir siswa. Agar mampu mengajak siswa masuk kedalam pengetahuan yang dimilikinya maka pembelajaran harus dirancang sebaik mungkin oleh guru yang tidak hanya ditampilkan dengan cara memberikan konsep, teori, dan fakta saja, melainkan melalui pengaplikasian pada ilmu yang dipelajari dalam kehidupan nyata sehari-hari. Untuk itu, salah satu mata pelajaran untuk mengaplikasikannya adalah pelajaran tematik.

Di dalam dunia pendidikan khususnya Sekolah Dasar (SD) tematik adalah salah satu bahan pelajaran yang saling terkait dengan mata pelajaran terpadu, seperti Matematika, Bahasa Indonesia, IPA, IPS, PJOK, PPKN dan mata pelajaran lainnya disatukan dengan menggunakan tema. Pada pelaksanaan pembelajaran yaitu pembelajaran tematik ada beberapa hal yang penting untuk dilakukan yaitu tahap perencanaan, adalah: pemetaan standar kompetensi yang merupakan penjabaran dari standar kompetensi dan kompetensi dasar, selanjutnya yaitu menentukan tema, dan mengidentifikasi standar kompetensi, kompetensi dasar serta indikator, lalu dengan menetapkan beberapa jaringan tema, dilanjutkan dengan penyusunan silabus, dimana pengertian silabus adalah rencana pembelajaran yang dilakukan pada suatu kelompok mata pelajaran atau tema tertentu yang terdiri dari standar kompetensi dasar, materi pokok pembelajaran, kegiatan pembelajaran, indikator pencapaian kompetensi penilaian, penilaian, alokasi waktu dan sumber belajar.

Pada pembelajaran tematik, penulis melihat dan mengamati berdasarkan dari pengalaman magang III bahwa siswa kewalahan dalam mengikuti pembelajaran karena guru masih menggunakan model 
konvensional, yang seabagian besar guru kurang mampu mengajak siswa untuk belajar lebih aktif pada saat proses belajar berlangsung dikarenakan guru sering kali lebih berpatokan terhadap materi yang diajarkan dan membuat beberapa siswa lebih tidak diperhatikan yang menyebabkan mencari cara untuk menarik perhatian guru dengan cara bermain-main pada saat guru menjelaskan, mengganggu teman kelasnya dan ada pula sebagian siswa tidak mengerti sama sekali dengan apa yang di ajarkan guru.

Masalah kedua seperti hasil belajar siswa SD RK Budi Luhur Medan Denai pada pelajaran temaVIII subtema I pembelajaran II, tergolong cukup rendah ini terlihat dari rendahnya nilai harian siswa. Hal tersebut dapat disebabkan oleh ketidakmampuan siswa dalam mengikuti pembelajaran yang dilaksanakan cenderung menggunakan model konvensional, sehingga hasil belajar siswa tidak maksimum sesuai yang diharapkan. Dalam proses pembelajaran sangat diperlukan oleh guru dalam menggunakan model pembelajaran agar suasana pembelajaran dapat berjalan dengan baik dan tercapai sesuai yang diharapkan. Untuk meningkatkan hasil belajar siswa, maka guru harus bisa memilih dan menggunakan model pembelajaran yang sesuai dengan mata pelajaran dan materi yang akan diajarkan, dalam hal ini model pembelajaran Take and Give dapat berguna dalam meningkatkan keaktifan siswa dalam proses pembelajaran di kelas.

Perlunya

model

pembelajaran yang bervariasi agar siswa tidak mudah merasa bosan dan dapat mengaktifkan siswa dalam proses pembelajaran. Guru harus bisa memilih salah satu model pembelajaran yang sesuai dengan materi pelajaran. Berbagai macam model pembelajaran yang dapat digunakan oleh guru untuk memberikan solusi dari permasalahan tersebut sehingga mampu membuat suasana proses belajar yang lebih aktif serta tidak merasa membosankan yaitu melalui menerapkan model pembelajaran Take and Give. Istilah Take and Give sering diartikan "saling memberi dan saling menerima". Kegiatan ini menjadi intisari dari model pembelajaran Take and Give. Model pembelajaran Take and Give yaitu sebuah strategi dalam pembelajaran yang didukung untuk penyajian data yang dimulai dengan pemberian kartu kepada siswa. Kegiatan tersebut mampu mengubah suasana kelas menjadi aktif saat belajar berlangsung.

Rendahnya hasil belajar siswa kelas III pada pelajarantema VIII subtema I pembelajaran II SD RK Budi Luhur Medan Denai, juga diakibatkan oleh siswa dengan cara belajar yang tidak serius saat pembelajaran dan kurang mendengar arahan dari guru, bahwa di rumah harus mengulang kembali pembelajaran dari sekolah. Berdasarkan hasil pengamatan dari Magang III penulis melihat bahwa 
guru kurang mampu menggunakan model pembelajaran sehingga nilai harian masih sangat rendah serta ketidaksesuaian dengan Kriteria Ketuntasan Minimal (KKM) yang sudah ditentukan oleh Sekolah tersebut yaitu 70 .

Proses kegiatan pendidikan di sekolah adalah merupakan kegiatan yang paling bermanfaat bagi siswa. Sebab keberhasilan atau tidaknya dalam mencapai suatu pendidikan pembelajaran itu dilihat dari seorang tenaga pengajar dalam proses menyampaikan pembelajaran. Dalam proses kegiatan tersebut, guru berperan sangat penting sehingga dituntut untuk mampu memberikan seluruh ilmu pengetahuan yang terdapat dalam dirinya/dimilikinya terhadap peserta didiknya.

Proses belajar di SD memiliki perbedaan dengan di SMP/SMA dimana siswa sangat berpaku kepada guru. Menjadi guru SD khususnya dapat memberikan tempat khusus yang cukup bagi siswa agar mampu mengembangkan kemandirian siswa, serta dapat memotivasi siswa dalam mengembangkan pengetahuan dan kemampuan dalam berpikir terhadap siswa. Dalam mencoba mengarahkan siswa kedalam sebuah pengetahuan maka pembelajaran harus dirancang oleh guru mata pelajaran yang mampu memberikan lebih dari sekedar konsep, teori, dan fakta saja, melainkan pengaplikasian ilmu yang dipelajari dalam kehidupan nyata sehari-hari. Maka salah satu mata pelajaran untuk mengaplikasikannya adalah pelajaran tematik.
Di dalam dunia pendidikan khususnya Sekolah Dasar (SD) tematik adalah salah satu bahan pelajaran yang saling terkait dengan mata pelajaran terpadu, seperti Matematika, Bahasa Indonesia, IPA, IPS, PJOK, PPKN dan mata pelajaran lainnya disatukan dengan menggunakan tema. Dalam pembelajaran tematik ada tahapan yang perlu dilakukan yang meliputi tahap perencanaan, yakni: yaitu tahap perencanaan, adalah: pemetaan standar kompetensi yang merupakan penjabaran dari standar kompetensi dan kompetensi dasar, selanjutnya yaitu menentukan tema, dan mengidentifikasi standar kompetensi, kompetensi dasar serta indikator, lalu dengan menetapkan beberapa jaringan tema, dilanjutkan dengan penyusunan silabus, dimana pengertian silabus adalah rencana pembelajaran yang dilakukan pada suatu kelompok mata pelajaran atau tema tertentu yang terdiri dari standar kompetensi dasar, materi pokok pembelajaran, kegiatan pembelajaran, indikator pencapaian kompetensi penilaian, penilaian, alokasi waktu dan sumber belajar.

Pada pembelajaran tematik, penulis melihat dan mengamati berdasarkan dari pengalaman magang III bahwa siswa kewalahan dalam mengikuti pembelajaran karena guru masih menggunakan model konvensional, yang seabagian besar guru kurang mampu mengajak siswa untuk belajar lebih aktif pada saat proses belajar berlangsung dikarenakan guru sering kali lebih berpatokan terhadap materi yang 
diajarkan dan membuat beberapa siswa lebih tidak diperhatikan yang menyebabkan mencari cara untuk menarik perhatian guru dengan cara bermain-main pada saat guru menjelaskan, mengganggu teman kelasnya dan ada pula sebagian siswa tidak mengerti sama sekali dengan apa yang di ajarkan guru.

Masalah kedua seperti hasil belajar siswa SD RK Budi Luhur Medan Denai pada pelajaran temaVIII subtema I pembelajaran II, tergolong masih rendah hal ini dapat dilihat dari nilai hasil harian siswa. Tingkat rendahnya hasil belajar dari siswa dikarenakan ketidakmampuan siswa dalam mengikuti kegiatan pembelajaran yang telah dilaksanakan cenderung menggunakan model konvensional, sehingga hasil belajar siswa tidak maksimum sesuai yang diharapkan. Dalam proses pembelajaran sangat diperlukan oleh guru dalam menggunakan model pembelajaran agar suasana pembelajaran dapat berjalan dengan baik dan tercapai sesuai yang diharapkan. Untuk meningkatkan hasil belajar siswa, maka guru harus bisa memilih dan menggunakan model pembelajaran yang sesuai dengan mata pelajaran dan materi yang akan diajarkan, dalam hal ini model pembelajaran Take and Give dapat berguna dalam meningkatkan keaktifan siswa dalam proses pembelajaran di kelas.

Perlunya model pembelajaran yang bervariasi agar siswa tidak mudah merasa bosan dan dapat mengaktifkan siswa dalam proses pembelajaran. Guru harus bisa memilih salah satu model pembelajaran yang sesuai dengan materi pelajaran. Salah satu Langkah atau model pembelajaran yang mampu dilakukan oleh guru untuk mengatasi beberapa permasalahan tersebut sehingga dapat memberikan suasana belajar yang aktif dan lebih menyenangkan adalah dengan menggunakan model pembelajaran Take and Give. Istilah Take and Give sering diartikan "saling memberi dan saling menerima". Prinsip ini menjadi intisari dari model pembelajaranTake and Give. Model pembelajaran Take and Give merupakan strategi pembelajaran yang didukung oleh penyajian data yang diawali dengan pemberian kartu kepada siswa. Hal ini dapat mengubah suasana kelas menjadi aktif saat belajar berlangsung.

Rendahnya hasil belajar siswa kelas III pada pelajarantema VIII subtema I pembelajaran II SD RK Budi Luhur Medan Denai, juga diakibatkan oleh siswa dengan cara belajar yang tidak serius saat pembelajaran dan kurang mendengar arahan dari guru, bahwa di rumah harus mengulang kembali pembelajaran dari sekolah. Berdasarkan hasil pengamatan dari Magang III penulis melihat bahwa guru kurang mampu menggunakan model pembelajaran sehingga nilai harian masih sangat rendah dan tidak sesuai dengan Kriteria Ketuntasan Minimal (KKM) yang sudah ditentukan oleh Sekolah tersebut yaitu 70 . 


\section{METODE PENELITIAN}

Penelitian ini menggunakan metode eksperimen, dengan secara langsung ke sekolah untuk memperoleh data-data yang dibutuhkan untuk mengetahui pengaruh model pembelajaran Take and Give. Sebagai populasi dan sampel dalam penelitian ini berjumlah 30 siswa kelas III SD RK Budi Luhur Medan berdasarkan teknik sampling jenuh. Dengan memberikan angket model pembelajaran Take and Give sebayak 17 pernyataan dan soal pretes, post-tes sebanyak 30 butir soal diberikan kepada siswa kelas III SD RK Budi Luhur Medan Tahun Pembelajaran 2020/2021. yang dibutuhkan untuk mengetahui pengaruh model pembelajaran Take and Give. Sebagai populasi dan sampel dalam penelitian ini berjumlah 30 siswa kelas III SD RK Budi Luhur Medan berdasarkan teknik sampling jenuh. Dengan memberikan angket model pembelajaran Take and Give sebayak 17 pernyataan dan soal pretes, post-tes sebanyak 30 butir soal diberikan kepada siswa kelas III SD RK Budi Luhur Medan Tahun Pembelajaran 2020/2021.

\section{HASIL PENELITIAN DAN PEMBAHASAN}

Pada bagian ini akan dideskripsikan gambaran mengenai pengaruh model pembelajaran Take and Give terhadap hasil belajar siswa tema praja muda karana kelas III SD RK Budi Luhur Medan Denai Tahun Pembelajaran 2020/2021.
Data pada variabel pengaruh model pembelajaran Take and Give terhadap hasil belajar siswa tema praja muda karana kelas III dengan menggunakan instrumen dengan 17 pernyataan dan 30 responden, setiap butir pernyataan jawaban. Berdasarkan perhitungaan statistik dasar yang diperoleh rata-rata (mean) 80,2 . Data yang diperoleh selanjutnya dibuat tabel fekuensi model pembelajaran yang secara singkat dapat dilihat pada tabel 1 .

Tabel 1. Frekuensi Angket

\begin{tabular}{l|l|l|l|l}
\hline No & Kls & F & Presentase & Kategori \\
\hline 1 & $91-98$ & 1 & $3,3 \%$ & Sangat tinggi \\
\hline 2 & $82-90$ & 19 & $63,3 \%$ & Tinggi \\
\hline 3 & $73-81$ & 3 & $10 \%$ & Cukup \\
\hline 4 & $64-72$ & 2 & $6,6 \%$ & Kurang \\
\hline 5 & $55-63$ & 5 & $1,5 \%$ & Rendah \\
\hline
\end{tabular}

Berdasarkan tabel frekuensi di atas, dapat diketahui bahwa skor 82-90 yang memiliki frekuensi siswa terbanyak dengan jawaban responden sebanyak $63,3 \%$ dengan kategori tinggi dengan jumlah 19 responden, selain itu paling rendah adalah skor 55-63 dengan jawaban 1,5\% dengan kategori rendah 5 responden.

Selanjutnya data pada nilai post-test yang sudah diberikan perlakuan dan dapat dilihat dari tabel 2 di bawah ini.

Tabel 2. nilai Post-test

\begin{tabular}{l|ll}
\hline Statistik & Post-test \\
\hline Jumlah subjek & 30 \\
\hline Mean & 86,7 & \\
\hline Standar Deviasi & 15,698 & \\
\hline Standar Eror & 2,17 & \\
\hline $\begin{array}{l}\text { Keterangan: Diberikan } \\
\text { pembelajaran Take and Give. }\end{array}$
\end{tabular}


Maka dapat dilihat nilai posttest berpengaruh dengan hasil belajar menggunakan model pemeblajaran, dapat dilihat dari gambar diagram dibawah ini.

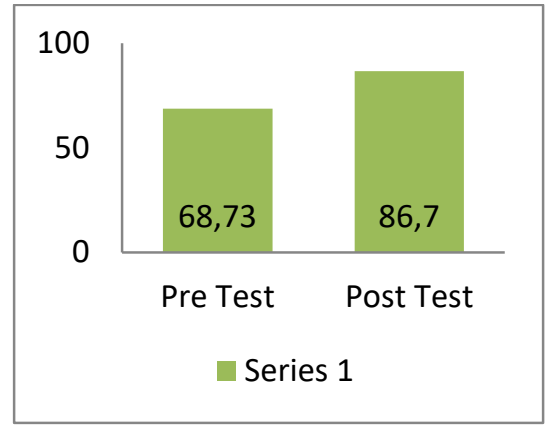

\section{Gambar Diagram 1. Hasil Belajar Siswa}

\section{Pembahasan}

Berdasarkan diagram tabel di atas dapat disimpulkan bahwa nilai eksperimen sebelum diberikan perlakuan (treatment) model pembelajaran Take and Give (pre test) nilai rata-rata adalah 68,73 sedangkan setelah diberikan perlakuan (treatment) model pembelajaran Take and Give nilai rata-rata adalah 86,7 dapat disimpulkan bahwa nilai ratarata post test sudah mencapai KKM 70.

Uji koefisien korelasi digunakan untukmengetahui ada tidaknya pengaruh antara variabel bebas (X) variabel terikat (Y), dan syarat untuk uji koefisien korelasi yaitu dengan melihat $\mathrm{t}$ hitung $>\mathrm{t}$ tabel dengan rumus korelasi product moment. Diperoleh hasil koefisien korelasi $\left(\mathrm{r}_{\mathrm{xy}}\right)$ atau $\mathrm{r}_{\text {hitung }}=0,576$ dengan taraf signifikan 5\% dengan jumlah responden $(n)=30$ siswa, sehingga diperoleh $r_{\text {tabel }}=0,361$. Dari hasil perhitungan tersebut menunjukkan bahwa $\mathrm{r}_{\text {hitung }} \geq \mathrm{r}_{\text {tabel }}$ maka dapat disimpulkan terdapat hubungan yang kuat antara model Take and Give dengan hasil belajar siswa kelas III SD RK Budi Luhur Medan Denai 95\%. Dan sebanyak 5\% dipengaruhi oleh faktor lain yang tidak dikaji dalam penelitian ini.

Tabel 3. Uji Koefisien Korelasi

\begin{tabular}{l|l|l|l}
\hline \multicolumn{2}{c|}{} & model & Hasil \\
\hline \multirow{7}{*}{ Model } & $\begin{array}{l}\text { Pearson } \\
\text { Correlation }\end{array}$ & 1 &, $578^{* *}$ \\
\cline { 2 - 4 } & $\begin{array}{l}\text { Sig. } \\
(2-\text {-tailed })\end{array}$ &, 001 \\
\cline { 2 - 4 } & $\mathrm{N}$ & 30 & 30 \\
\hline \multirow{5}{*}{ Hasil } & $\begin{array}{l}\text { Pearson } \\
\text { Correlation }\end{array}$ &, $578^{* *}$ & 1 \\
\cline { 2 - 4 } & $\begin{array}{l}\text { Sig. } \\
(2-\text {-tailed })\end{array}$ &, 001 & \\
\cline { 2 - 4 } & $\mathrm{N}$ & 30 & 30 \\
\hline
\end{tabular}

\section{Pembahasan}

Berdasarkan hasil perhitungan yang dilakukan, diperoleh hasil koefisien korelasi $\left(\mathrm{r}_{\mathrm{xy}}\right)$ atau $\mathrm{r}_{\text {hitung }}$ $=0,578$ dengan diperoleh $r_{\text {tabel }}=0,361$.

Dari hasil perhitungan tersebut menunjukkan bahwa $r_{\text {hitung }} \geq r_{\text {tabel}}$, maka dapat disimpulkan hipotesis alternatif ( $\mathrm{Ha}$ ) diterima yaitu terdapat hubungan positif yang signifikan antara model Take and Give (X) dengan hasil belajar siswa (Y) kelas III SD RK Budi Luhur Medan Denai.

Setelah data dinyatakan berdistribusi normal dan sampel bersal dari populasi yang sama atau homogen, maka selanjutnya dapat dilakukan pengujian hipotesis menggunakan "uji t". Statistik yang digunakan untuk menguji hipotesis 
penelitian adalah uji-t. Hipotesis yang diajukan adalah,

$H_{O}$ : Tidak ada pengaruh model model pembelajaran Take and Give terhadap hasil belajar siswa

$H_{\alpha}$ : ada pengaruh model pembelajaran Take and Give terhadap hasil belajar siswa.

Kriteria uji-t dapat dilakukan signifikan apabila diperoleh harga $\mathrm{p}<0,05$ serta hipotesis diterima $\left(H_{\alpha}\right)$ jika $t_{\text {hitung }}>\mathrm{t}_{\text {tabel }}$ $(1-\alpha)$ dan tidak diterima $\left(H_{0}\right)$ jika $t_{\text {hitung }}<t_{\text {tabel }}(1-\alpha)$.

Hasil perhitungan diperoleh bahwa Nilai thitung sebesar 3,268 dan $t_{\text {tabel }}$ sebesar 1,697 sehingga $t_{\text {hitung }} \geq$ $\mathrm{t}_{\text {tabel }}$ maka $\mathrm{Ho}$ diterima yaitu terdapat model Take and Give (X) mempunyai pengaruh positif dan signifikan terhadap hasil belajar siswa (Y).

\section{SIMPULAN}

Berdasarkan pembahasan bab ini peneliti menguraikan kesimpulan, implikasi, keterbatasan penelitian dan saran yang disusun berdasarkan seluruh kegiatan penelitian mengenai pengaruh model pembelajaran Take and Give terhadap hasil belajar siswa di SD RK Budi Luhur Medan Denai Tahun Pembelajaran 2020/2021 sebagai berikut:

- Hasil belajar siswa sebelum dilakukan perlakuan diperoleh nilai rata-rata pretest 68,85 . Setelah diberikan perlakuan dengan model pembelajaran Take and Give maka diperoleh nilai rata-rata posttes jaitu 86,7.
- Peneliti memberikan angket model pembelajaran Take and Give dengan nilai rata-rata 80,2 .

- Dari hasil pengolahan data diperoleh nilai signifikan model Take and Give adalah 0,200 $\geq 0,05$ hasil belajar siswa signifikannya $0,200 \geq 0,05$. Berdasarkan hasil perhitungan tersebut dapat diketahui bahwa nilai signifikansi dari model Take and Give dan hasil belajar siswa lebih besar dari 0,05 dapat disimpulan bahwa hasil belajar siswa berdistribusi normal.

- Hasil peneltian ini menunjukkan bahwa model pembelajaran Take and give memiliki hubungan dengan hasil belajar siswa. Hal tersebut terbukti dari $\mathrm{r}_{\mathrm{xy}} 0,578$. Berdasarkan tabel interpretasi nilai $\mathrm{r}$, kolerasi $\mathrm{r}_{\mathrm{xy}} 0,578$ terletak pada rentang nilai r 0,800 - 1,000 maka, dapat disimpulkan adanya pengaruh model Take and Give dengan hasil belajar siswa memiliki hubungan yang sangat tinggi.

- Dari hasil penelitian uji hipotesis (uji t) menunjukkan bahwa model Take and Give memiliki pengaruh yang positif dan signifikan, hal tersebut terbukti dari nilai $t_{\text {hitung }} \geq$ $t_{\text {tabel }}$ sebesar 3,268 $\geq 2,024$. Maka dengan demikian Ha diterima yaitu ada pengaruh yang signifikan antar model Take and Give (X) dengan hasil belajar siswa $(\mathrm{X})$.

\section{DAFTAR RUJUKAN}

Anwar, \& Harmi. 2011. Perencanaan Sistem Pembelajaran Kurikulum Tingkat Satuan Pendidikan (KTSP) (2nd ed.). Bandung: 
Jontono Samosir, Regina Sipayung, Reflina Sinaga, Darinda Sofia Tanjung : Pengaruh ...

Alfabeta.

Asna, A. 2019. Pengaruh Penggunaan

Model Pembelajaran Take And

Give Terhadap Hasil Belajar

Siswa Pada Pembelajaran

Tematik Kelas V Min 1 Metro

Tahun Pelajaran 2018 / 2019

Jurusan: Pendidikan Guru

Madrasah Ibtidaiyah (PGMI)

Fakultas: Tarbiyah Dan Ilmu

Keguruan.

Dalyono. 2012. Psikologi Pendidikan (7th Ed.). Jakarta : Rineka Cipta.

Djamarah. 2019. Psikologi Belajar (3rd Ed.). Jakarta : Rineka Cipta.

Fathurrohman. 2015. Model-Model

Pembelajaran Inovatif (N.

Hidayah (Ed.); 1st Ed.).

Semarang: Ar-Ruzz Media.

Hamalik. 2013. Kurikulum Dan Pembelajaran (12th Ed.).

Bandung: Bumi Aksara.

Khairani. 2013. Psikologi Belajar.

Bandung: Aswaja Pressindo.

Kompri. 2018. Motivasi Pembelajaran

Prespektif Guru Dan Siswa (A.

Kamsyach (Ed.); 2nd Ed.).

Jakarta : Remaja Rosdakarya

Offset.

Kurniasih, \& Sani. 2016. Ragam

Pengembangan Model

Pembelajaran Untuk

Peningkatan Profesionalitas

Guru (A. Jay (Ed.); 4th Ed.).

Bandung: Kata Pena.

Manullang, \& Pakpahan. 2014. Metodologi Penelitian (1st Ed.).
Medan: Perdana Mulya Sarana.

Mudjiono, \& Dimyati. 2015. Belajar Dan Pembelajaran (5th Ed.).

Bandung: Asdi Mahasatya.

Prastowo. 2014. Pengembaangan Bahan Ajar Tematik (1st Ed.). Bandung: Prenada Media Group. Priansa. 2015. Manajemen Peserta Didik Dan Model Pembelajaran (A. Kasmanah (Ed.); 1st Ed.). Jakarta: Alfabeta.

Purwanto. 2011. Evaluasi Hasil Belajar (B. Santosa (Ed.); 3rd Ed.). Bandung: Pustaka Pelajar.

Siswanto, \& Ariani. 2016. Model Pembelajaran Menulis Cerita (1st Ed.). Bandung: Refika Aditama.

Slameto. 2017. Belajar Dan FaktorFaktor Yang Mempengaruhi (5th Ed.). Jakarta: Rineka Cipta.

Sugiyono. 2017. Metode Penelitian Kuantitatif, Kualitatif, Dan $R$ \& $D$ (25th Ed.). Bandung: Alfabeta. Susanto. 2013. Teori Belajar Dan Pembelajaran Di Sekolah Dasar (4th Ed.). Semarang: Prenadamedia Group.

Yulianti, \& Yuniasih. 2019. Telaah Kurikulum. Banten: Media Sutra Atiga.

Yusuf, \& Sugandhi. 2013. Perkembangan Peserta Didik (4th Ed.). Bandung: Rajagrafindo Persada. 